\title{
Operative treatment of posterior spinal arachnoid cysts: do not refrain from checking on an anterior transdural spinal cord herniation
}

\author{
Rob J. M. Groen • Maarten H. Coppes
}

Received: 26 October 2010 /Accepted: 19 November 2010/Published online: 4 January 2011

(C) The Author(s) 2010. This article is published with open access at Springerlink.com

\section{Dear Editor,}

We read with much interest the recent paper by Baba et al. [1] about posterior thoracic arachnoid cysts (PAC) causing spinal cord compression symptoms. The authors report three operative cases, diagnosed with MRI techniques, in which they were able to intraoperatively record the pulsatile effects of the arachnoid cyst on the spinal cord by means of transdural ultrasound. The cysts were removed, and the decompression and realignment of the spinal cord were confirmed with postoperative MRI.

As the authors pointed out, isolated symptomatic posterior arachnoid cysts are rare. After the introduction of MRI, the number of reported cases has increased. Nevertheless, surgical experience with this entity within single institutions will remain limited, which underlines the relevance of their present paper for the readership. In this perspective, we feel that it is likewise relevant to point out another important item, related to the differential diagnosis of PAC, that has not been addressed by the authors.

Preoperative diagnosis of PAC not is always straightforward, despite the use of modern imaging techniques like MRI and CT myelography. In addition, intraoperative ultrasound can be helpful. Nevertheless, as is known from the literature and from our own experience, PAC can occur simultaneously with another rare entity, i.e., anterior transdural spinal cord herniation (ATSCH). Recently, we reported a review of all the published cases with ATSCH.

R. J. M. Groen $(\varangle) \cdot$ M. H. Coppes

Department of Neurosurgery, University Medical Center

Groningen, State University of Groningen,

PO Box 30001, 9700 RB, Groningen, The Netherlands

e-mail: r.j.m.groen@nchir.umcg.nl
It appeared that, at least in eleven cases, the initial diagnosis was PAC. The patients were operated on as such (posterior intradural exploration with resection of a posterior (thoracic) arachnoid cyst), but nevertheless, they experienced ongoing neurological deterioration. Re-exploration was performed, and finally, an ATSCH was detected and treated accordingly [2]. So, whenever a PAC is suspected, the clinician should be aware of the possibility that the patient might suffer ATSCH. Besides, both conditions may exist simultaneously in the same patient $[3,4]$.

The definitive diagnoses can only be made during operation. In case of a suspected PAC, even when such a cyst is actually found, the surgeon should proceed to explore and to thoroughly inspect the ventral portion of the spinal cord and the dural sac. Bilateral trans-section of the denticulate ligaments is needed in order to mobilize and lift the cord and to properly expose the relevant anatomical structures. In case that a dural defect and cord herniation are found, the cord should be de-tethered and/or released, and measures should be taken to prevent a re-herniation. This can be done either by widening of the defect of the dura (as is promoted in most of the Japanese papers) or by the application of a patch or sleeve that covers the dural defect [2].

Much has been speculated about the etiology of ATSCH and PAC. It is not known whether the anterior displacement of the thoracic spinal cord (for example, due to compression by a posterior arachnoid cyst) plays a role in the occurrence of a defect in the anterior part of the dural sac and subsequent transdural spinal cord herniation. Apparently, however, both conditions may occur in a single patient and in the same cord area (which, almost exclusively, is in the thoracic spinal region). The clinician should be aware of the possibility of 
such a condition, and the operation should be planned in such a way that both problems can be detected and treated in the same stage. Otherwise, the patient might unnecessarily be at risk for a progressive and potentially irreversible, additional neurological deficit and might need a re-exploration that could have been prevented.

\section{Conflicts of interest None.}

Open Access This article is distributed under the terms of the Creative Commons Attribution Noncommercial License which permits any noncommercial use, distribution, and reproduction in any medium, provided the original author(s) and source are credited.

\section{References}

1. Baba T, Koyanagi I, Yoshifuji K, Murakami T, Houkin K (2010) Pulsatile wall movement of spinal arachnoid cyst deteriorates spinal cord symptoms: report of three cases. Acta Neurochir 152:12451249

2. Groen RJ, Middel B, Meilof JF, de Vos-van de Biezenbos JB, Enting RH, Coppes MH, Journée LH (2009) Operative treatment of anterior thoracic spinal cord herniation: three new cases and an individual patient data meta-analysis of 126 case reports. Neurosurgery $64: 145-160$

3. Tronnier VM, Steinmetz A, Albert FK, Scharf J, Kunze S (1991) Hernia of the spinal cord: case report and review of the literature. Neurosurgery 29:916-919

4. Wada E, Yonenobu K, Kang J (2000) Idiopathic spinal cord herniation: report of three cases and review of the literature [in French]. Neurochirurgie 45:225-231 